\title{
A STUDY ON TEACHING AND LEARNING MODEL OF UNDERGRADUATE CODING EDUCATION USING ARDUINO
}

\author{
Jin-Hee $\mathrm{Ku}^{1 *}$ \\ ${ }^{1}$ Division of Liberal Education, Mokwon University, Republic of Korea \\ 1jhku@mokwon.ac.kr
}

\begin{abstract}
Technologies leading to the fourth industrial revolution, such as ubiquitous mobile internet, powerful sensors, and artificial intelligence, are rapidly changing our daily lives and industrial structure through the Internet of Things (IoT). As a result, computer programming is now regarded as an essential skill for 21 st century students, and coding education aimed at promoting computational thinking is becoming a core component of curriculums not only in elementary and middle schools, but also in universities. In particular, the rapid development of the IoT, which is one of the main technologies enabling the connection between real objects and the digital sphere, has resulted in a need for more undergraduate coding education in many universities. This study proposed a teaching and learning model for IoT concepts that utilizes Arduino for the coding education of undergraduate students, and analyzed its effectiveness. In order to understand the concept of the IoT, students organized project scenarios related to real-world subjects, and added creative designs. Each team then implemented IoT project works using five sensors and actuators. A questionnaire was used to evaluate the effectiveness of the model, the results of which confirmed that the teaching approach helped to improve the students' understandings of the IoT and better understand the technologies underlying the fourth industrial revolution technology in general, as well as gain the coding abilities to implement new ideas in the digital sphere.
\end{abstract}

Keywords - Arduino, Coding Education, Computational Thinking, Internet of Things, Teaching Model, Undergraduate

\section{INTRODUCTION}

As more and more objects in our daily lives become connected to the Internet, the "Internet of Things" (IoT) has become a rapidly developing sphere of data, responsible for providing us with many intelligent services. Digital connectivity created on the basis of software technologies, in the era of the Fourth Industrial Revolution, is fundamentally changing society. One of the key technologies that enables the connectivity between the real and the digital is the IoT, which is essentially formed from the relationship between objects (products, services, places, etc.,) and humans, based on smart sensors and various platforms [1]. The rapid development of IoT applications is expected to steadily increase the demand for skilled workers in this area in the coming years. In light of this, it is clearly necessary to study the basic concept of IoT in undergraduate coding education in order to better prepare the next generation workforce.

Received: May 6, 2019

Reviewed: August 12, 2019

Accepted: August 31, 2019

* Corresponding Author 
Coding education is not only about acquiring a programming language, it is also proposed as an optimal way to cultivate thinking that expresses the abstract (Abstraction) thinking that is required to solve real-world problems using a computer and automated (Automation) methods [2-5]. Coding education is not just for students pursuing a major in computer programming; it can also be beneficial for students who want to gain a better overall understanding of modern technology and how it shapes our world $[6,7]$.

The use of Arduino is very effective as a teaching method for the conceptual learning of IoT principles, that integrates cyber and physical systems as well as an introduction to programming $[8,9]$. Arduino can accept values from multiple switches and sensors, and control external electronic devices such as LEDs and motors, to create objects that can interact with the environment. Designed to allow students who are not familiar with hardware to easily control their design work, Arduino can be used to control custom device using a coding structure that is easily developed using one of its embedded systems $[10,11]$.

In recent years, as the manpower requirements of the software field have increased greatly, many Korean universities, including software oriented universities, are increasing coding education for non-majors as well. This is because almost all industries are now operated by some form of software, and almost all of us interact with such softwares in one way or another, even if we are not all software engineers [6]. Many universities have thus been teaching Scratch, C, Excel, and Python for years now however there are still few subjects that deal with the IoT. To address this, this study utilized the Arduino-based IoT integration project, which is linked with a cloud server, to propose and test a teaching and learning model of undergraduate coding education using Arduino, and to analyze its effectiveness for teaching IoT concepts. The teaching and learning model for coding education was based on the design thinking model, and the concrete teaching and learning method was based on project learning.

\section{DESIGN OF TEACHING AND LEARNING}

An Instructional-design theory is a theory that offers explicit guidance on how to better help learners learn and develop [12]. In this section, we propose a teaching and learning model applicable to software education and computational thinking enhancement [13, 14], and construct the teaching and learning methods according to the IoT project learning situations.

\subsection{DESIGN THINKING PROCESS MODEL}

Design Thinking is a design methodology that provides a solution-based approach to solving problems. The design-centered model follows the design thinking process presented at Stanford University's D-school. The process of design thinking carries out a human-centered needs analysis through the process of immersion through exploration. We recognize that SW development is not merely the development of mechanical programs, but also the improvement and optimization of human life and activities in general through complex and creatively-designed program structures. The creation of new prototypes or simulations through the design and development process is an excellent way to enhance computational thinking; it has a cyclical nature that constantly finds new routes to improvement through the sharing and evaluation of results. 


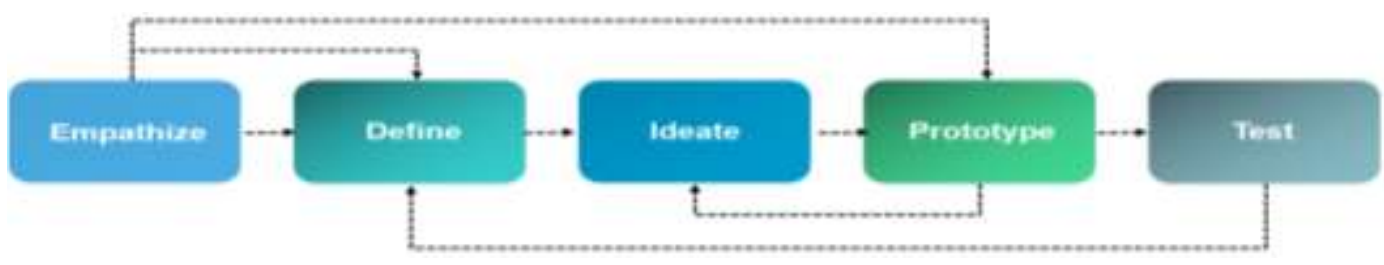

Fig. 1 Five stages in the Design Thinking process: Design Thinking is a design methodology that provides a solution-based approach to solving problems [15]

2.1.1. EMPATHIZE: The first stage of the Design Thinking process is to gain an empathic understanding of the problem you are trying to solve [15]. Empathy is the centerpiece of a human-centered design process. The Empathize stage encompasses the work you do to understand people, within the context of your design challenge. It is your effort to understand the way they do things and why, their physical and emotional needs, how they think about world, and what is meaningful to them [16]. To gain empathy, you must observe user and user behavior in the context of the real world, because you first need to know the user in order to make meaningful innovations.

2.1.2. DEFINE THE PROBLEM: This stage focuses on human-centered observations and the analysis of user needs. Human-centered needs analysis aims to better the software's value in a developmental direction of benefit to the end user, unlike purposeless software development [14]. The definition phase pays more attention to requirement analysis and the design process than to the development process.

The problem definition phase is the step of synthesizing insights about users' needs and their problems in a discrete sense - not broadly - into a concrete statement [16].

2.1.3. IDEATE: The ideate phase has a very broad scope including the design of the development-oriented model. Beyond simply drawing out a design, this stage focuses on expanding our thinking and producing creative ideas. Before implementing it in a programming language, it is necessary to understand the project's story, necessary objects, characteristics and roles of objects, and interaction between objects [14]. Visualization techniques can be applied to decompose problems and find patterns among the components for fueling computational thinking at the ideate stage. Visualization techniques use a variety of strategies such as mind maps, brainstorming, graphs, and diagrams, to enhance creative thinking $[15,17]$.

2.1.4. PROTOTYPE: This is an experimental phase, where the aim is to identify the best possible solution for each of the problems identified during the first three stages. The solutions are implemented within the prototypes, and, one by one, they are investigated and either accepted, improved and re-examined, or rejected [15][17].

The prototype stage comprehensively expands computational thinking through programming and the implementation of physical computing (such as through Arduino) [18][19]. In the design thinking model, the selection of the subject, the needs analysis, the design of the creative solution, and the strategy of the implementation are carried out as student-centered activities. The teacher acts as a facilitator and curator of the projectbased class.

2.1.5. TEST: The stage of testing encompasses the whole process of invention and production, beyond simply introducing the produced work. In this stage of self-reflection, the developers make a fundamental evaluation of human-centered needs analysis and design. This stage helps students understand computing power, abstraction, and automation through their teacher's comments and advice on their tested prototype [14]. 
Students should decide for themselves the overall need for correction and supplementation of their products using requirements analyses, design and implementation through the evaluation results, opinions, and self-reflection discussions in the sharing stage. Testing is the chance for students to refine their solutions and make them better.

\subsection{PROJECT BASED LEARNING DESIGN FOR IOT PROJECTS}

In this study, the software learning model was designed based on the design thinking model and project learning. The project-based learning model is a teaching model that allows students to participate in the whole process of learning, from the stage of selecting the topic with the awareness of the problem by the students themselves, to the investigation, research, presentation, and evaluation, rather than these tasks being taken on solely by the instructor. In contrast to the traditional teaching model, the instructor in a project-based learning system should act as a guide to help students get meaningful learning outcomes through active feedback. In this study, based on the models of the design thinking process and project-based learning, each IoT project is constructed according to the learning situation.

2.2.1. DATA COLLECTION: In this stage, relevant data is collected and analyzed in order to identify a problem. This step is analogous to the Empathize stage of the design thinking model. This is where the project title is selected and an outline of the work to be done is made. An example of this stage's output may be a statement such as: "Build your own smart home by implementing IoT ideas".

2.2.2. SUBJECT SELECTION: In this stage, the title and work outline of the project are refined, and methods to help solve problems are identified. In this study, Arduino was used as the main method to help students understand the concepts behind the IoT, rather than requiring them to simply learn a computer program or a block of code alone. In the example of the smart home, students would be encouraged to look around them - nearly every modern appliance and piece of electronics has at least one microcontroller (or little computer) that controls touchscreens, indicator LEDs, alarms, etc.

2.2.3. PROJECT PLAN WRITING: This process involves collecting and analyzing data from problem definitions and synthesizing ideas. At this stage, a conceptual design should be presented, after instructor feedback is received on the plan. Fig. 2 is an example of a conceptual diagram of the smart home IoT project.

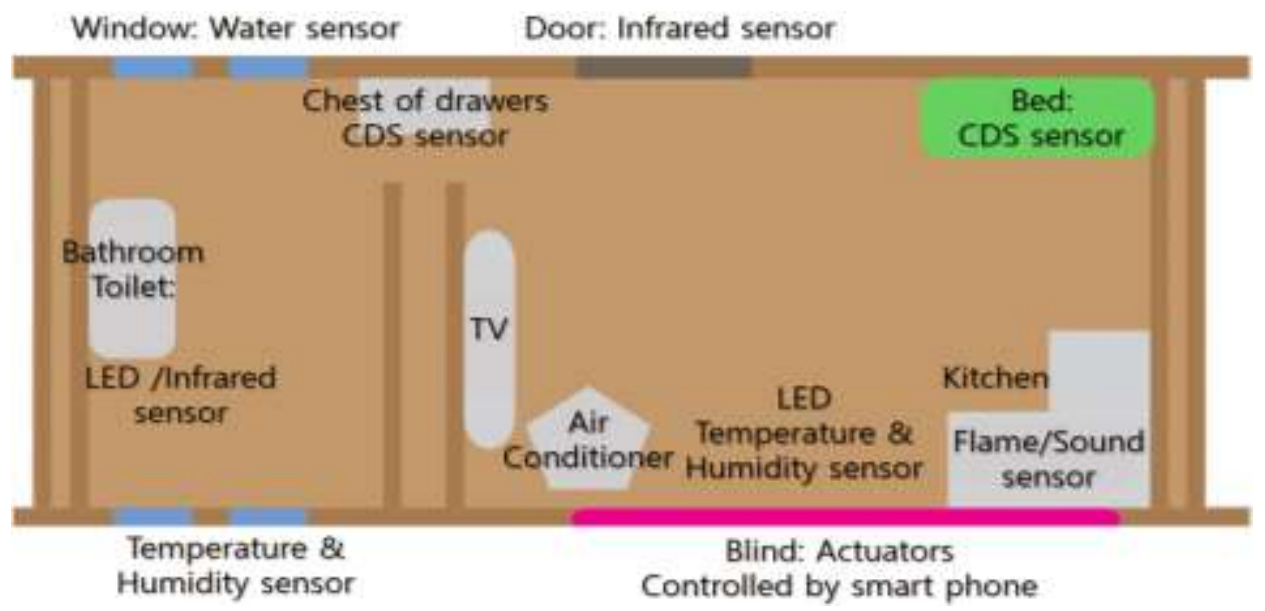

Fig. 2 A conceptual design of the overall task configuration is presented in the definition phase of the design thinking process, which is based on data collection. 
2.2.4. PROJECT IMPLEMENTATION: Project tasks are then executed by the students. The results of the performance are analyzed by the instructor, and feedback is given to the students. Table I shows the Arduino, sensors, and components used in this teaching model, and their specifications. Figure 3 shows the various sensors connected to the Arduino board.

Table I. Components for IoT Project

\begin{tabular}{|c|c|c|}
\hline Component & Specification & Quantity \\
\hline Orange board BLE & Arduino UNO R3(+BLE) & 1 \\
\hline USB cable & 5 Pin Micro USB & 1 \\
\hline Bread board & 830 Pin & 1 \\
\hline RGB LED & KY-016 & 3 \\
\hline CDS('Cadmium Sulfide) sensor & KY-018 & 1 \\
\hline Temperature\&Humidity sensor & DHT-11 & 1 \\
\hline Infrared sensor & FC-51 & 1 \\
\hline Water sensor & Water level sensor & 1 \\
\hline Flame sensor & Analog flame sensor & 1 \\
\hline Sound sensor & SZH-EK033 & 1 \\
\hline \multirow[t]{2}{*}{ Resistance } & $1 / 8 \mathrm{WJ} 10 \mathrm{~K} \Omega$ & 10 \\
\hline & $1 / 4 \mathrm{WJ} 330 \mathrm{~K} \Omega$ & 10 \\
\hline Laser Module & KY-008 & 1 \\
\hline NeoPixel LED & RGB & 1 \\
\hline \multirow[t]{2}{*}{ High brightness LED } & White Color(5Pi) & 2 \\
\hline & BLUE Color(5Pi) & 2 \\
\hline Button & $12 \times 12 \times 7 \mathrm{~mm}$ & 2 \\
\hline Piezo buzzer & MSES12C & 1 \\
\hline Servo motor & SG90 & 1 \\
\hline $12 \mathrm{C} \mathrm{LCD}$ & SZH-EK101 & 1 \\
\hline \multirow[t]{4}{*}{ Cable } & F/M 30cm & 40 \\
\hline & $\mathrm{F} / \mathrm{M} 20 \mathrm{~cm}$ & 20 \\
\hline & $\mathrm{M} / \mathrm{M} 20 \mathrm{~cm}$ & 10 \\
\hline & $\mathrm{M} / \mathrm{M} 10 \mathrm{~cm}$ & 10 \\
\hline
\end{tabular}

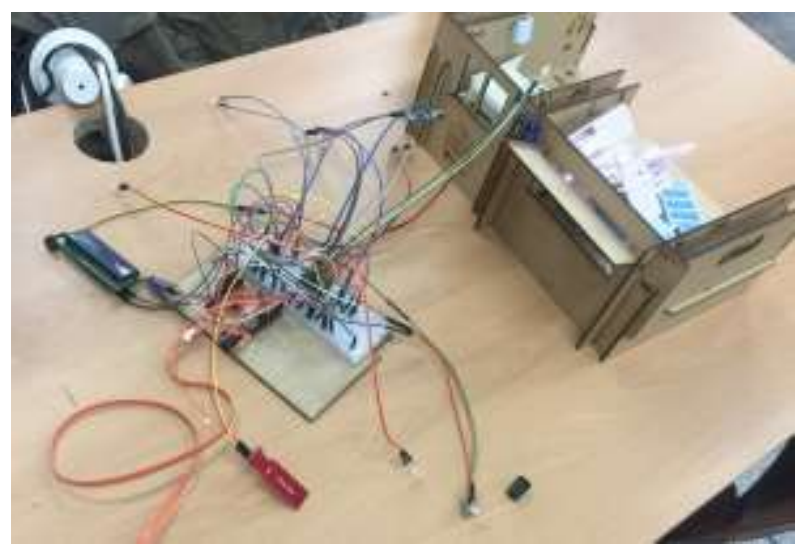

Fig. 3 Sensors and actuators connected to Arduino. Evaluate the circuit arrangement status in complete

This IoT project demonstrated how the Arduino Uno development board, the DHT11 temperature and humidity sensor, and the WiFi module, could be used to monitor ambient temperature and humidity over the Internet. Arduino is good to use in coding education 
because it can create and modify boards directly and is easier to program than other physical computing devices [20,21]. The data collected by the sensors is processed by the Arduino board, sent to the WiFi module, then sent to the cloud servers on the IoT ThingSpeak platform for real-time storage, analysis, and graphical display.

Figure 4 (a) and (b) show temperature/humidity measurement from the DHT11 sensor and (c) shows the code to upload the measured sensor values to the ThingSpeak cloud server.

In addition, the data transmitted to the Arduino board can be monitored by a smartphone in conjunction with an open-source cloud system such as ThingSpeak. Figure 5 shows the monitoring temperature/humidity sensor data collected from the Arduino.

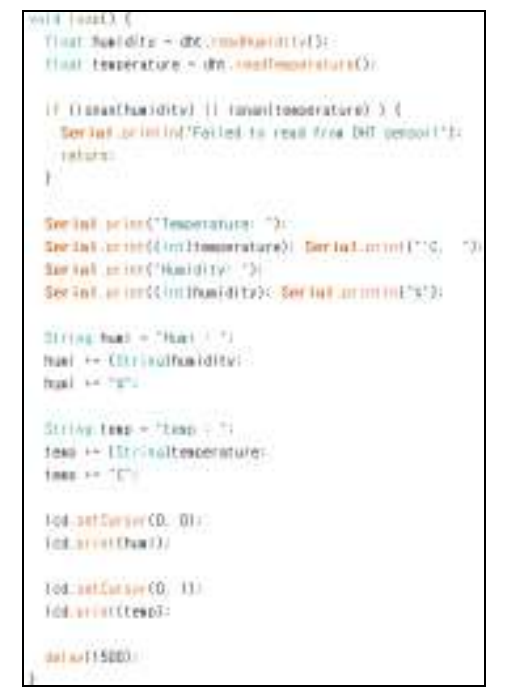

(a)

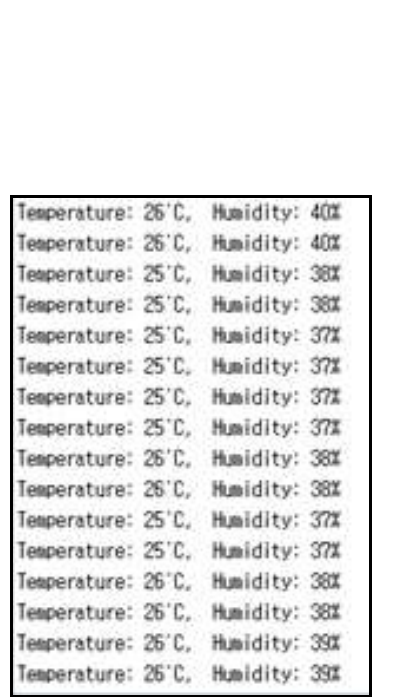

(b)

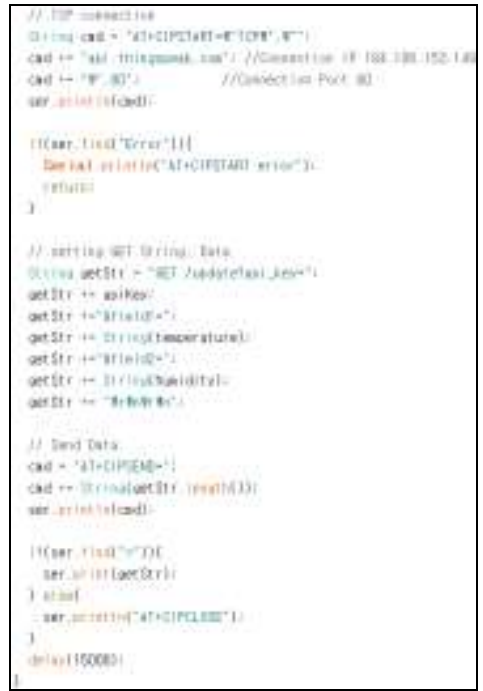

(c)

Fig. 4 (a) Code to measure temperature/humidity on the DHT11 sensor, and output to $\mathrm{I}^{2} \mathrm{C}$ LCD, (b) temperature/humidity values, and (c) code to transfer data to ThingSpeak

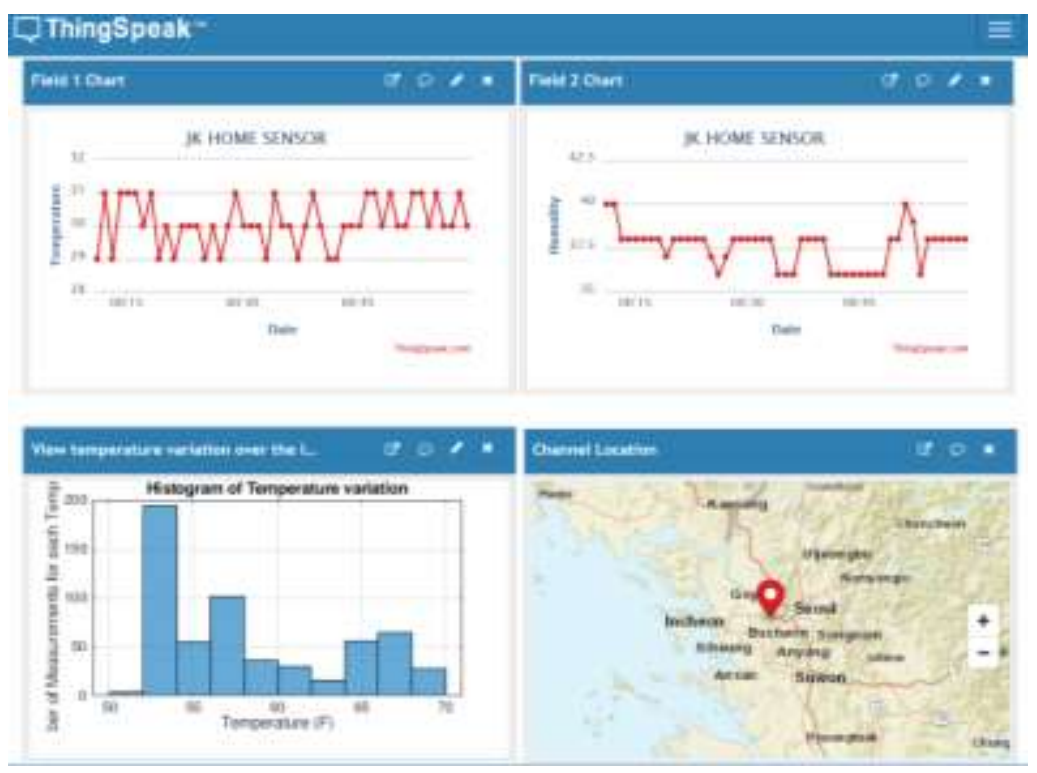

Fig. 5 Monitor temperature / humidity sensor data from Arduino on ThingSpeak My Channel

2.2.5. RESULT REPORT WRITING AND EVALUATION: In this stage students report the results of the project. The results of each project are presented to the rest of the 
group, and reflection/evaluation is conducted in a shared environment. Qualitative evaluation of the work and quantitative evaluation of the project's performance are done by both the peers and the instructor.

\section{RESULTS AND DISCUSSION}

\subsection{RESULT OF LEARNING ACTIVITIES}

The undergraduates' IoT project outcomes evaluated five criteria: originality of ideas, appropriate sensor usage, IoT component implementation (sensor operation), completeness (appearance, arrangement), and project presentation. Figure 6 and 7 are examples of IoT works.

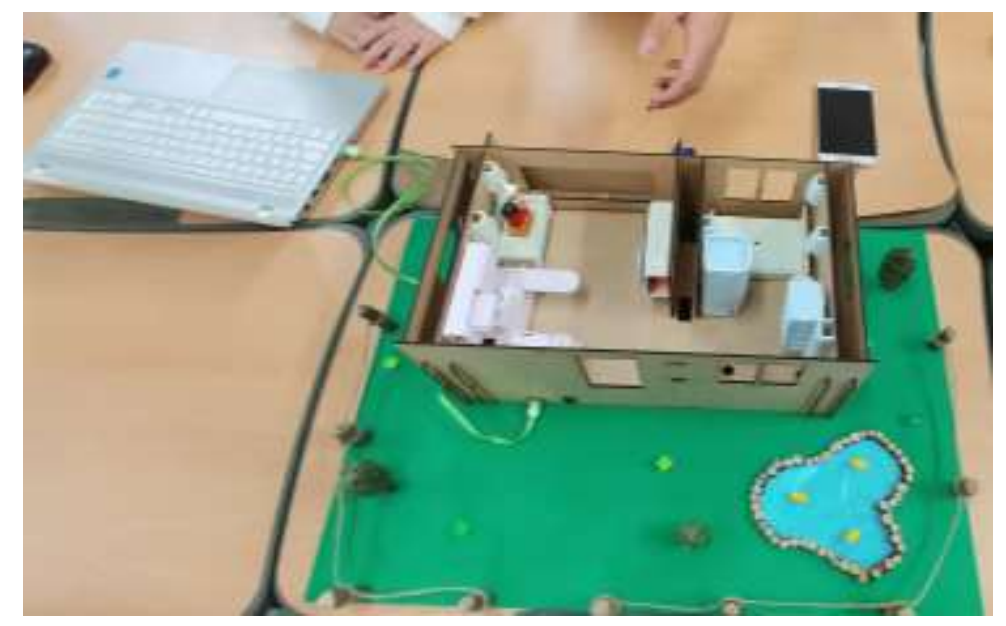

Fig. 6 Example of a student IoT project creating a miniaturized smart home

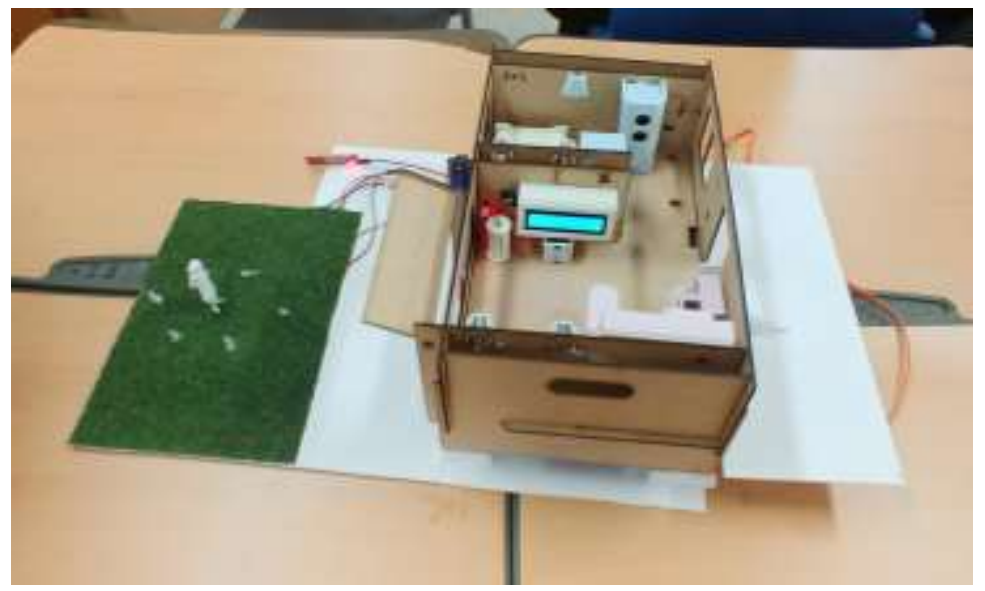

Fig. 7 Another Example of IoT work that implemented smart home idea scenarios of a team

In the miniaturized smart-home project, when the user sent a control signal from their smartphone to the application, it transmitted and received data from the Arduino using Bluetooth communication. The data received from the smartphone was then sent back to the sensor and actuator control module in the Arduino, to perform the desired operation. Arduino works with a wide variety of programming tools; Figure 8 shows the program using Entry instead of Sketch, Figure 9 (a) shows a design screen of a Bluetooth connection app created in an app inventor to control the Arduino using a smartphone, and (b) is a program block-diagram of (a). Arduino control is also possible using the nRF 
Toolbox app(The nRF Toolbox is a container app that stores your Nordic Semiconductor apps for Bluetooth Low Energy in one location), too.

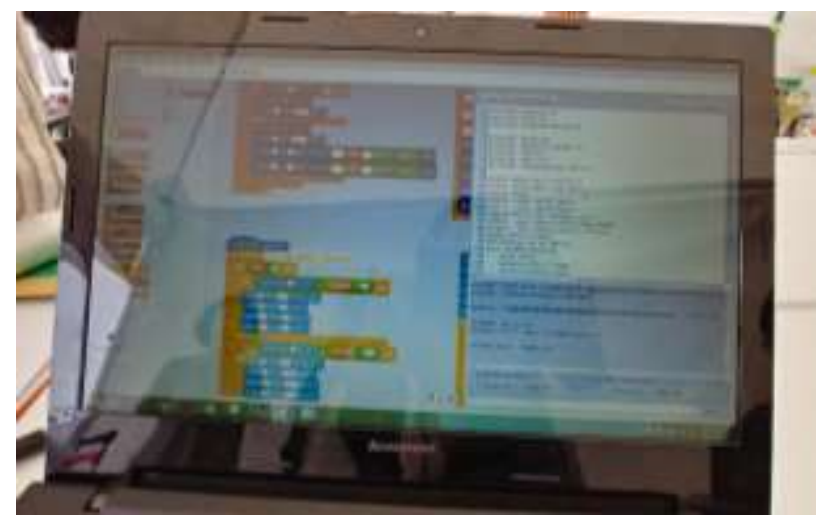

Fig. 8 Arduino control program written in an entry

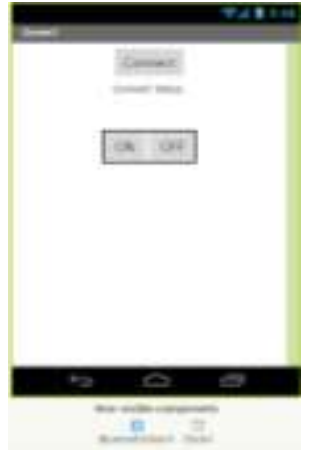

(a)

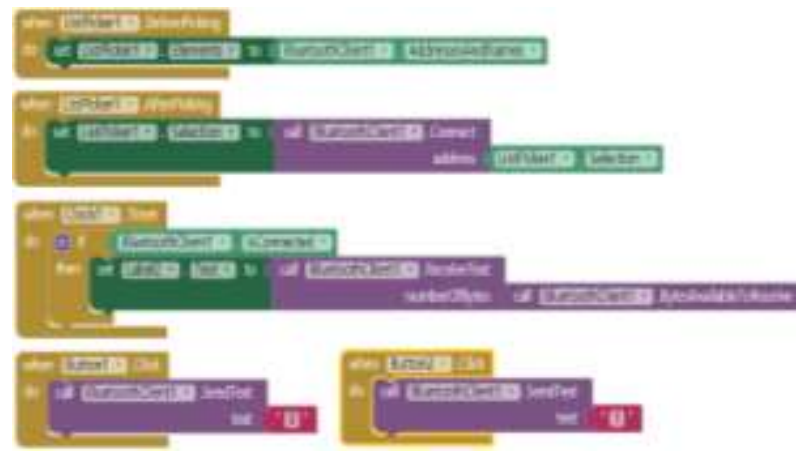

(b)

Fig. 9 (a) Design screen of a Bluetooth connection app created in an app inventor to control the Arduino using a smartphone, and (b) program block-diagram of the app

\subsection{EVALUATION OF TEACHING APPROACH}

A questionnaire was prepared for 58 first-year students in the program. This Study conducted pre-program and post-program surveys on the appreciation of the class, understanding of computing technology, coding ability for idea implementation, and applied teaching and learning methods.

All students were familiar with the $\mathrm{C}$ programming language prior to being enrolled in the module, but did not know any others. All students reported that they were learning Arduino for the first time. A relatively high average rise was found in the understanding of technologies, including IoT, by the students after the module. In the post-program survey, the average self-evaluated ratings of students' coding abilities for idea implementation increased, but showed slight differences compared to pre-program survey scores. Many students answered that they had difficulty designing a program to implement an idea, but this class was interesting and helpful in understanding the concepts of IoT, cloud, and big data. 


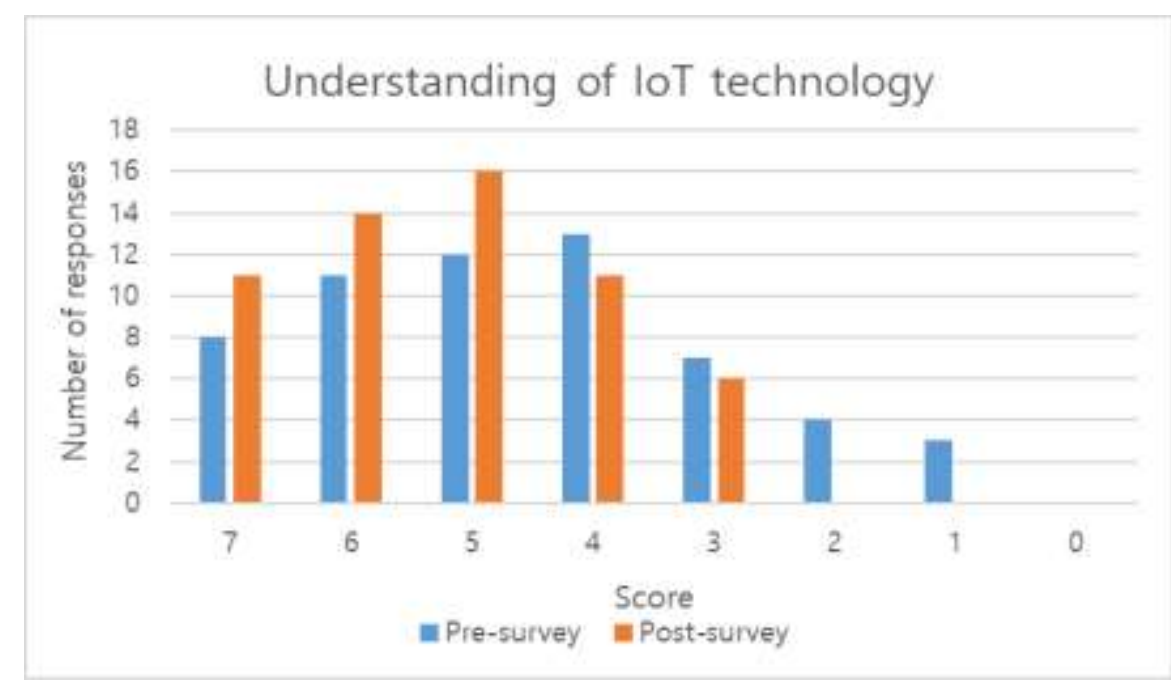

Fig. 10 Pre-program and post-program survey results on understanding of IoT technology

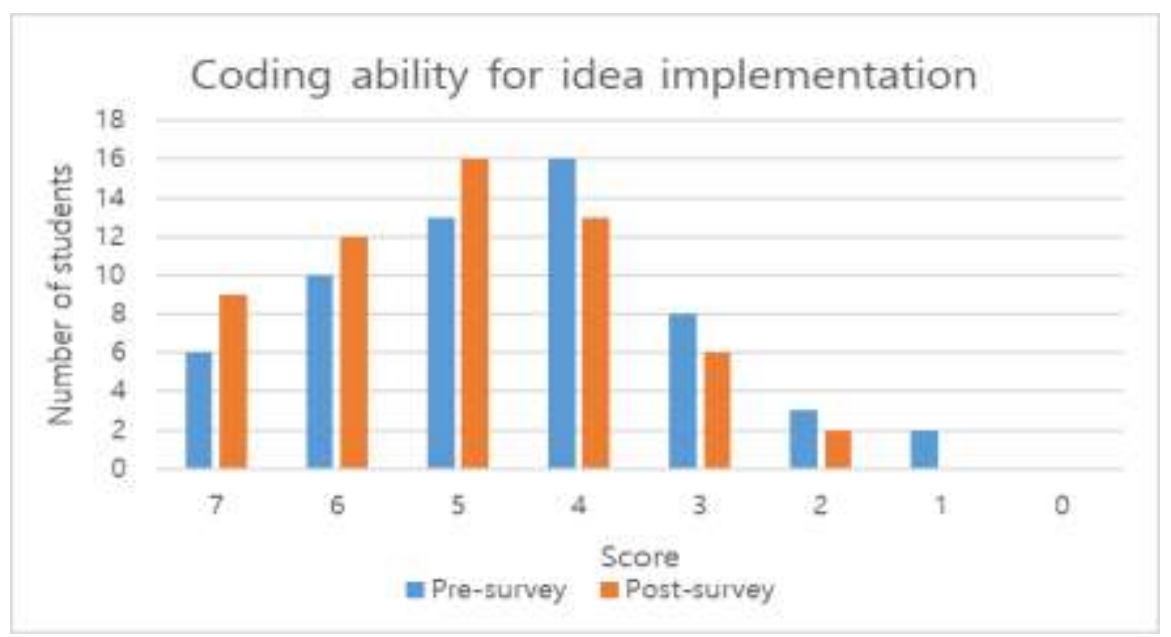

Fig. 11 Pre-program and post-program survey results on coding ability for idea implementation

\section{CONCLUSION}

The IoT, which connects many objects in our daily lives to the Internet, is rapidly developing. Teaching people about this new platform is now becoming necessary at the undergraduate level, even for majors outside of the coding disciplines. This study proposed a project-based teaching and learning model for teaching IoT concepts that utilized Arduino for the coding education of undergraduate students, and analyzed its effectiveness. Many simplified programming languages have been created to introduce beginners to programming. This study suggested Arduino specifically as a suitable structure for learning IoT in an undergraduate introductory programming course.

Coding education is important to improve computational thinking and software convergence ability for both computer science majors and university students in other streams. In order to achieve this goal, the design thinking model and project-based learning methods were constructed to enhance software education and computational thinking ability. It is expected that the teaching and learning model in this study can be used to effectively introduce computer science and the programming languages to beginners. 


\section{REFERENCES}

[1] Schwab, Klaus. The Fourth Industrial Revolution. London: Portfolio Penguin, 2017.

[2] Wing, JM., "Computational Thinking.", Communication of the ACM 49.3 (2006): 33-35.

[3] Wing, JM., "Computational thinking and thinking about computing." Philosophical Transactions of The Royal Society 366 (2008): 3717-3725.

[4] Lee, M. S., "A Study on Creative and Convergent SW Education Programs for improving Computational Thinking", Journal of The Korea Society of Computer and Information 22.8 (2017): 93100.

[5] Ku, J. H. "A Study on the Software Convergence Education for Non-Majors Computer Science using Creative Robot." Journal of the Korea Academia-Industrial cooperation Society 18.2 (2017): 631-638.

[6] Stenger, Marianne. Coding In Education: Why It's Important \& How It's Being Implemented. November 2017. https://www.opencolleges.edu.au/informed/features/coding-education-importantimplemented/

[7] Rossano, V., et al. "Conding and Computational Thinking with Arduino" International Conference on Cognition and Exploratory Learning in Digital Age, Budapest, Hungary, 21-23 October 2018. International Association for Development of the Information Society, 2018, pp. 263-269.

[8] Wikipedia. “Arduino.” Accessed 28 March 2019. https://en.wikipedia.org/wiki/Arduino

[9] Brinkmeier, M., et al. "A Case Study of Physical Computing in Computer Science Education" The 11th Workshop in Primary and Secondary Computing Education, Münster, Germany, 13-15 October 2016. ACM, 2016, pp. 54-59.

[10] Brock, JD., et al. "Using Arduino for Introductory Programming Course: A Tutorial." Journal of Computing Sciences in Colleges 25.2 (2009): 129-130.

[11] Park, Y. M. "The Arduino based Windowfarm Monitoring System." Journal of the Korea AcademiaIndustrial cooperation Society 19.5 (2018): 563-569.

[12] Reigelruth, Charles M. Instructional-Design Theories and Models, Volume II: A New Paradigm of Instructional Theory. Mahwah, NJ: Lawrence Erlbaum Assoc, 1999.

[13] Pearson. "Teaching \& Learning Design Principles." Accessed 28 March 2019. https://www.pearson.com/corporate/efficacy-and-research/teaching-learning-design-principles.html

[14] Kim, J. S., et al. A Study on Development of Teaching and Learning Model for Software Education. Korean Educational Development Institute, 2015.

[15] Dam, R., et al. "5 Stages in the Design Thinking Process." International Design Foundation, April 2019. https://www.interaction-design.org/literature/article/5-stages-in-the-design-thinking-process

[16] Institute of Design at Stanford, An Introduction to Design Thinking PROCESS GUIDE, https://dschoolold.stanford.edu/sandbox/groups/designresources/wiki/36873/attachments/74b3d/ModeGuideBOOTCA MP2010L.pdf

[17] Gashaye Melaku Tefera, "STAGES OF DESIGN THINKING", June 15, 2019, https://atlascorps.org/stages-of-design-thinking/

[18] Jun-Hyeong Lee, Hyeong-Ok Lee.Design of education program used physical computing for improving the computational thinking: applying Rubrics list.International Journal of Urban Design for Ubiquitous Computing. Vol. 6. No. 2. Sep. 2018.GVPress. pp:1-6.http://dx.doi.org/10.21742/IJUDUC.2018.6.2.01

[19] Youngho Lee.Development of Problem Solving Path Algorithm for Individualized Programming Education.International Journal of Advanced Research in Big Data Management System. Vol. 2. No. 1. Jun. 2018.GVPress. pp:7-12.http://dx.doi.org/10.21742/IJARBMS.2018.2.1.02

[20] Hong, Y. J., et al. "A study on lighting system for LED color temperature control using wireless communication and smartphone." Journal of the Korea Academia-Industrial cooperation Society 18.11 (2017): 72-77.

[21] Gaurav Panwar, Rajat Maurya, Rajesh Rawat, Rohit Kanswal and Praful Ranjan.Home automation using IOT application.International Journal of Smart Home. Vol. 11. No. 9. Sep. 2017.GVPress. pp:1 8.http://dx.doi.org/10.21742/IJSH.2017.11.9.01 